\title{
Preserving our international heritage of education in congenital heart surgery
}

\author{
Charles D. Fraser, Jr, MD, FACS
}

One of the many exciting and gratifying aspects of being a congenital heart surgeon (or any surgeon for that matter) is that the "language" of our specialty is universal, transcending international boundaries. In fact, the heritage of surgical progress in North America - in clinical practice and innovation, in surgical education, and in research - is inextricably linked to a long-standing history of international relationships. While their individual stories are too numerous to recount, most, if not all, of the surgical giants of the last century can trace a critical component of influence on their success to some form of international surgical experience. It is well known that William Stewart Halsted and Harvey Cushing made frequent trips to Europe throughout their storied careers to study with and observe leading surgeon scientists of their era, such as Kocher, Billroth, Mikulicz, and Volkmann. After completing his training in surgery at the Johns Hopkins Hospital under Alfred Blalock (and participating in the first "blue baby" operation), Denton Cooley moved his young family to London, England, for a year so that he could work with Lord Russell Brock and other notable British thoracic surgeons who were engaged in attempts at direct correction of congenital heart defects, primarily right ventricular outflow tract obstruction.

Until very recently, there has been a pervasive and probably legitimate belief among aspiring young congenital heart surgeons that some form of meaningful clinical experience abroad would truly embellish the likelihood of a successful career. A large proportion of the American leaders in our field in the past several decades can trace their early career paths back to important clinical fellowships around the world. From a personal perspective, the experience and knowledge that I gained as a fellow in congenital heart surgery at the Royal Children's Hospital in Melbourne, Australia, under the direction of Roger B. B. Mee was transformational in my career trajectory as a young surgeon, an experience I will cherish for the rest of my life.

\footnotetext{
From the Division of Congenital Heart Surgery, Michael E. DeBakey Department of Surgery, Baylor College of Medicine, Houston, Tex.

Disclosures: Author has nothing to disclose with regard to commercial support.

Received for publication May 2, 2014; accepted for publication May 5, 2014.

Address for reprints: Charles D. Fraser, Jr, MD, FACS, Surgeon-in-Chief, Chief, Clayton Chair in Surgery, Donovan Chair and Chief, Congenital Heart Surgery, Texas Children's Hospital, Professor of Surgery and Pediatrics, Baylor College of Medicine, 6621 Fannin St, MC-WT 19345H, Houston, TX 77030 (E-mail: CDFraser@texaschildrens.org).

J Thorac Cardiovasc Surg 2014;148:377-8

$0022-5223 / \$ 36.00$

Copyright (c) 2014 by The American Association for Thoracic Surgery http://dx.doi.org/10.1016/j.jtcvs.2014.05.009
}

I was recently privileged to visit the Great Ormond Street Hospital for Sick Children in London to deliver the 2014 David J. Waterston memorial lecture. During my visit, I questioned my gracious host, Professor Victor Tsang (also a Royal Children's Hospital alumnus) about recent interest in congenital heart surgery fellowships at Great Ormond Street from graduates from cardiothoracic residency programs in the United States. I was dismayed and disappointed to learn that since the institution of the 1-year American Board of Thoracic Surgery (ABTS) fellowship in congenital heart surgery in 2005, there has not been a single fellow from the United States at Great Ormond Street. Further informal query to my colleagues who direct congenital heart surgery programs around the world confirms an important and, to my view, concerning pattern. Graduates from cardiac surgery and congenital heart surgery training programs in the United States appear to have stopped seeking additional international training.

I view this as an unfortunate and unintended consequence of the institution of the ABTS Congenital Cardiac Surgery Fellowship process. Having participated in a small way in the early dialog and work that ultimately led to the development of the ABTS Congenital Cardiac Surgery Fellowship, I recognize that this was an important and much needed step forward in the formal education of aspiring congenital heart surgeons. Before the development of this fellowship, the quality of experience of the informal fellowship process was highly varied in both content and quality. I remain a strong supporter of the ABTS Congenital Cardiac Surgery Fellowship program. Nonetheless, I have serious concern that in the realm of congenital heart surgery, we in the United States are at risk of becoming intellectually isolated in our ever-changing specialty.

In writing this, I am in no way intending to impugn the ABTS Congenital Cardiac Surgery Fellowship or to discourage young cardiac surgeons from participating in one of the formal fellowships in congenital heart surgery in the United States, where residents are known to benefit from a tremendous educational opportunity. What I hope to achieve in this commentary, however, is to replant the seed of the idea of an additional formal clinical experience abroad. I am very sensitive to the perceived additional burden this implies: trainees in congenital heart surgery have typically experienced very long prerequisite periods of surgical education, have significant debt encumbrance, and, as such, are justified in being anxious to get on with their careers. Nonetheless, I reiterate the premise that a 
meaningful clinical experience in another country could have a major positive impact on not only one's clinical preparedness but also ultimate success.

There are many ways to practice the specialty of congenital heart surgery successfully and many perspectives on the management and specific surgical methodologies for treatment of complex conditions. Practice environments differ widely as do resources. As we travel the world to learn from our colleagues, all of us as congenital heart surgeons, no matter how experienced, pick up pearls of insight, wisdom, and experience that we bring home and apply to the benefit of our patients. We also experience the rich experience of cultural and social interactions that are forged through the lifelong professional and social relationships we develop with our colleagues in surgery around the world. This all can start with a fellowship abroad, where our minds may be opened to new ways of thinking and innovating. Our international relationships are an integral part of the history of congenital heart surgery and are critical to the future of our specialty. 